\title{
Article \\ Comparison of Machine Learning Approaches with Traditional Methods for Predicting the Compressive Strength of Rice Husk Ash Concrete
}

\author{
Muhammad Nasir Amin ${ }^{1, *(\mathbb{D})}$, Ammar Iqtidar ${ }^{2} \mathbb{D}$, Kaffayatullah Khan $^{1}{ }^{\mathbb{D}}$, Muhammad Faisal Javed ${ }^{2}$ (D), \\ Faisal I. Shalabi ${ }^{1}$ (D) and Muhammad Ghulam Qadir ${ }^{3}$
}

Citation: Amin, M.N.; Iqtidar, A.; Khan, K.; Javed, M.F.; Shalabi, F.I.; Qadir, M.G. Comparison of Machine Learning Approaches with Traditional Methods for Predicting the Compressive Strength of Rice Husk Ash Concrete. Crystals 2021, 11, 779. https://doi.org/10.3390/ cryst 11070779

\section{Academic Editors: Yang Yu,}

Weiqiang Wang, Rafael Shehu and Beatrice Pomaro

Received: 29 May 2021

Accepted: 1 July 2021

Published: 3 July 2021

Publisher's Note: MDPI stays neutral with regard to jurisdictional claims in published maps and institutional affiliations.

Copyright: (c) 2021 by the authors. Licensee MDPI, Basel, Switzerland. This article is an open access article distributed under the terms and conditions of the Creative Commons Attribution (CC BY) license (https:// creativecommons.org/licenses/by/ $4.0 /)$.
1 Department of Civil and Environmental Engineering, College of Engineering, King Faisal University, Al-Ahsa 31982, Saudi Arabia; kkhan@kfu.edu.sa (K.K.); fshalabi@kfu.edu.sa (F.I.S.)

2 Department of Civil Engineering, COMSATS University Islamabad, Abbottabad Campus, Abbottabad 22060, Pakistan; ammariqtidar@gmail.com (A.I.); arbabfaisal@cuiatd.edu.pk (M.F.J.)

3 Department of Environmental Sciences, COMSATS University Islamabad, Abbottabad Campus, Abbottabad 22060, Pakistan; hashir785@gmail.com

* Correspondence: mgadir@kfu.edu.sa; Tel.: +966-13-589-5431; Fax: +966-13-581-7068

\begin{abstract}
Efforts are being devoted to reducing the harmful effect of the construction industry around the globe, including the use of rice husk ash as a partial replacement of cement. However, no method is available to date to predict the compressive strength (CS) of rice husk ash blended concrete (RHAC). In this study, advanced machine learning techniques (artificial neural network, artificial neuro-fuzzy inference system) were used to predict the CS of RHAC. Based on the published literature, six inputs, i.e., age of specimen, percentage of rice husk ash, percentage of superplasticizer, aggregates, water, and amount of cement, were selected. Results obtained from machine learning methods were compared with traditional methods such as linear and non-linear regressions. It was observed that the performance of machine learning methods was superior to traditional methods for determining the CS of RHAC. This study will prove beneficial in minimizing the cost and time of executing laboratory experiments for designing the optimum content portions of RHAC.
\end{abstract}

Keywords: rice husk ash; compressive strength; ANN modeling; ANFIS modeling; construction industry; concrete

\section{Introduction}

Concrete is considered the most versatile and extensively used human-made material for infrastructure development on the earth. The annual production of concrete is estimated to be around 30 billion tons [1,2]. The global consumption of concrete is increasing day by day due to rapid urbanization in emerging countries. Cement, which is the main constituent of concrete, is a major contributor to greenhouse gases and is responsible for around $7 \%$ of total global carbon dioxide emissions [1-3]. In addition, with the increase in the fuel prices around globe, the per unit cost of cement has also increased [4]. Keeping in view these concerns about the environment, the cost of construction materials, the shortage of raw materials, and the high energy demand, the practice of utilizing alternate materials for construction is becoming a common concern across the globe.

Supplementary cementitious materials (SCMs) are materials that can be used as a partial replacement for ordinary Portland cement (OPC). Currently, there are numerous industrial and agricultural waste materials in practice that are being used as SCMs all over the world. The most widely used SCMs are fly ash (FA), sugarcane bagasse ash (SCBA), rice husk ash (RHA), volcanic ash (VA), electric arc furnace slag (EAFS), zeolite (ZLT), metakaolin (MK), and silica fume (SF). The utilization of agricultural waste in the construction industry will be a smart choice as it will reduce the harm caused by agricultural and construction industries to the environment. As cement is the most expensive ingredient 
of concrete, replacing it with potential agricultural waste materials will be beneficial to both the environment and the construction industry.

The percentage replacement of cement is determined based on the physical and chemical properties of waste material. Using SCMs in concrete may affect the different properties of concrete. Some SCMs may increase the durability of concrete while adversely affecting the CS of concrete. Hence, it is necessary to evaluate the physical and chemical properties of SCMs before their usage in concrete. In addition, the calculation of the optimum percentage of SCMs is important to obtain the best quality of concrete. According to past studies, RHA can be utilized as an SCM in concrete because of its high amount of silica (more than 90\%) [5]. The chemical composition of RHA is presented in Figure 1 [6]. A vast number of studies were carried out in the past to study the effect of RHA on different properties of concrete. Figure 2a shows the number of RHA-related articles published in each year since 2000. The significant increasing trend during the last five years (Figure 2a) shows the importance and feasibility of RHA as a potential SCM. Furthermore, most of the research on RHA is carried out by agricultural countries in which the construction industry is in a boom (Figure $2 b$ ).

Ameri et al. [7] observed that the early CS of RHAC increased robustly, yet it was limited by the amount of RHA. An increase in the RHA content to $15 \%$ resulted in decreased CS due to the excess amount of unreactive silica. The CS of RHAC was 9, 12, 13, and 16\% higher than the normal OPC mix. Likewise, Chao-Lung et al. [8] used RHA as an SCM and concluded that RHAC imparted a CS 1.2 to 1.5 times higher than that of the normal OPC mix. Similarly, Chindaprasirt et al. conducted [9] research to test RHAC for sulfate attack resistance and concluded that RHAC showed greater resistance to sulfate attack. Moreover, Thomas et al. [10] highlighted that the dense microstructure of RHA can reduce the water absorption of concrete by $30 \%$. Besides some technical benefits, numerous studied were conducted on the environmental impact of RHA. For instance, Gursel et al. [11] conducted research on the utilization of RHA in cement concrete and found it useful in reducing the global warming potential. Similar research was conducted by Moraes et al. [12], where they found that the use of RHA in cement mortar aided in reducing the harmful impacts on the environment due to cement. Therefore, based on the findings of the above-mentioned studies, RHA can be successfully utilized as an SCM as it inherits a carbon footprint much smaller than that of OPC. Its applications can be varied from structural concrete to sulfateresistant concrete. Hence, it can contribute towards the stability as well as durability of modern structures in a sustainable way [13].

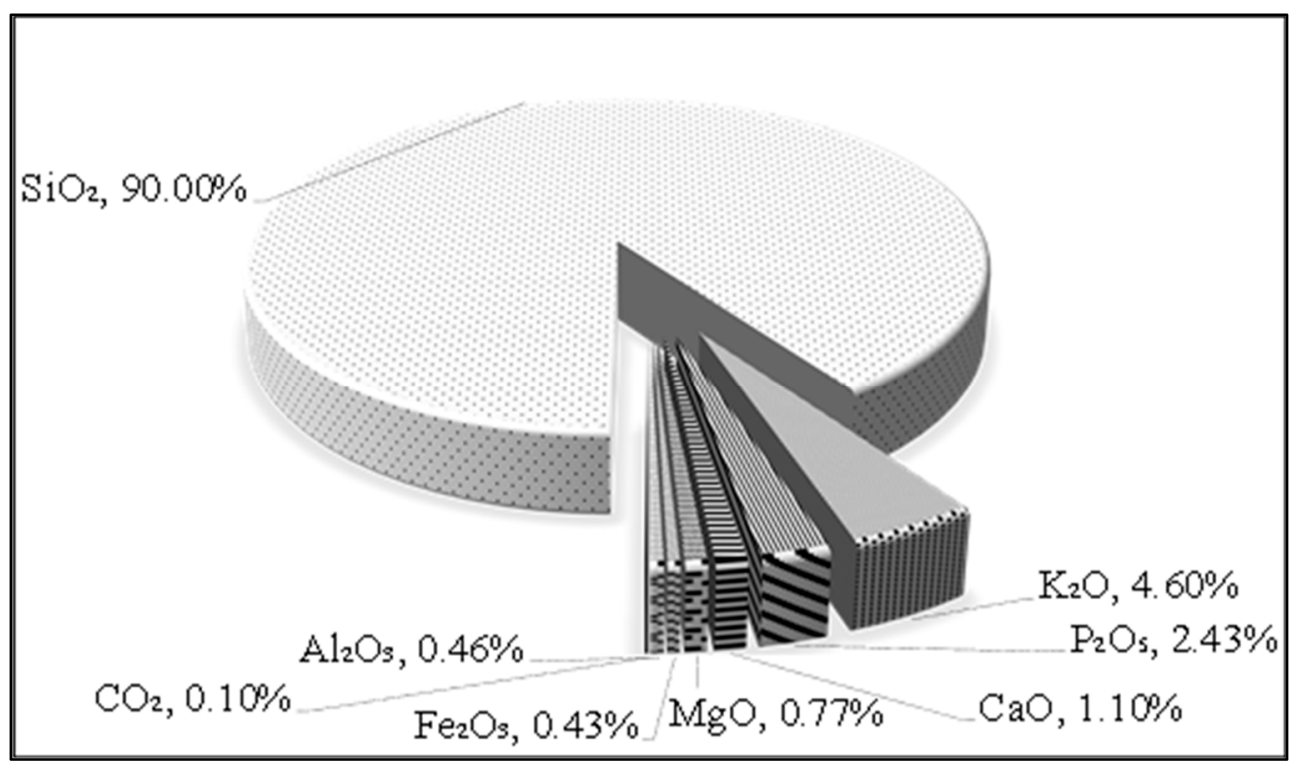

Figure 1. Chemical composition of RHA. 


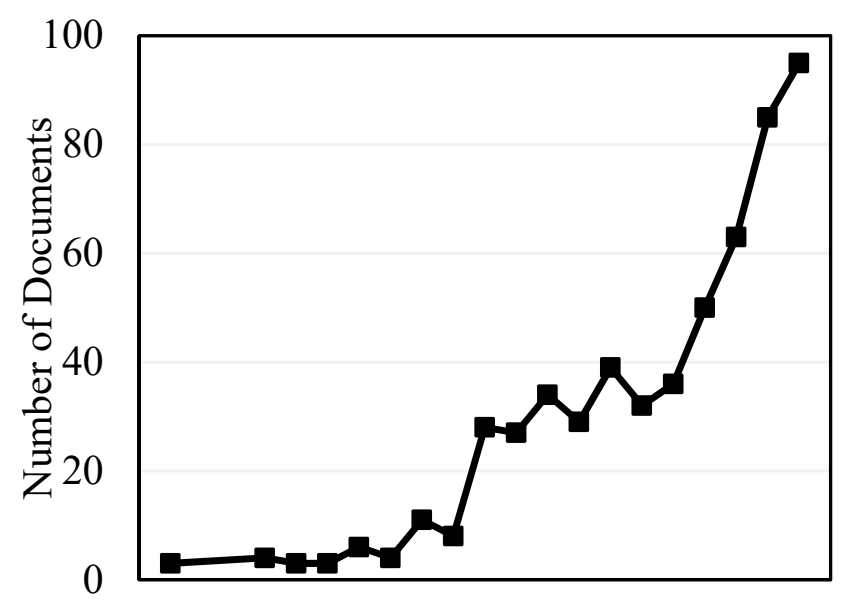

19992002200520082011201420172020

\section{Publication Year}

(a)

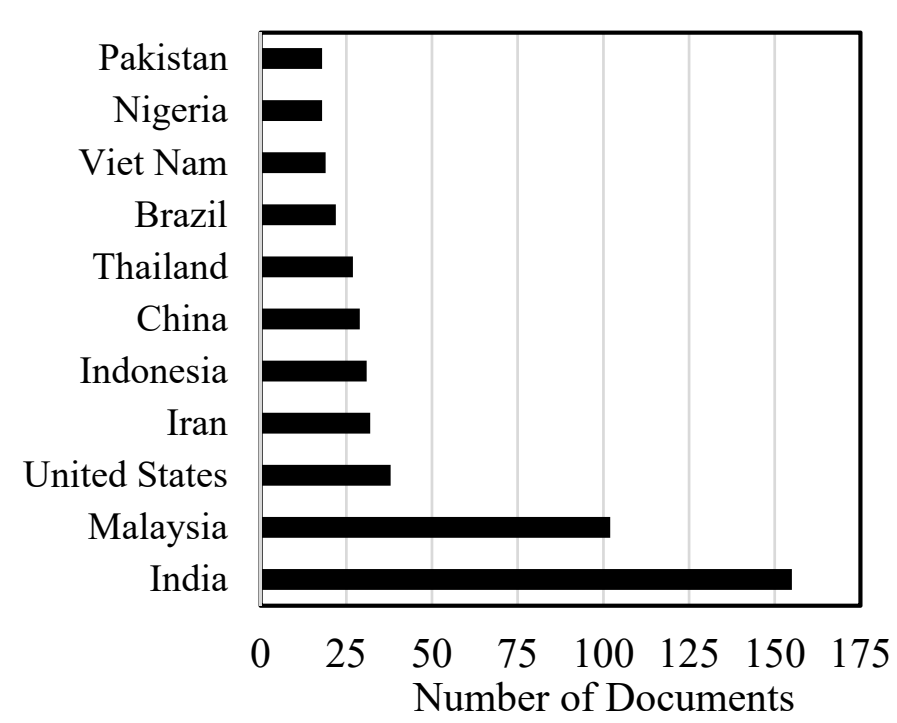

(b)

Figure 2. Research conducted on RHA: (a) during last two decades, and (b) by different agricultural countries (source: Scopus, date of accessing data: 25 May 2021).

A substantial amount of time is required to develop and carry out extensive testing of RHA. The rate at which the environment is constantly degrading does not provide much time to carry out testing and research on RHA. As a result, RHAC cannot be subjected to ample lab work. Moreover, the hygroscopic nature of RHA makes it difficult to devise a certain control mix. Consequently, artificial intelligence (AI) is being used on a large scale to predict the properties of different SCMs. These properties also include the CS of different mixes. Some of the AI techniques (Table 1) used to model and predict the properties of different materials are artificial neural networks (ANNs), artificial neuro-fuzzy interface systems (ANFISs), gene expression programming (GEP), support vector machines (SVMs), backpropagation neural networks (BPNNs), extreme learning machines (ELMs), multiple non-linear regression (MNLR), linear regression (LR), and response surface methodology (RSM) $[14,15]$. Much research is conducted on RHAC by using and comparing different techniques. However, no research has been conducted thus far through a comparison with RSM.

In this research, four programming techniques were used: ANN, ANFIS, RSM, and LR. Since AI is a complex programming process and a great optimization is required to attain high accuracy, the results obtained from these four techniques will be compared with each other as well as with experimental data obtained from the literature to assess the accuracy. For modeling, a vast database of the peer-reviewed literature was obtained. 
Table 1. Some recent studies using AI.

\begin{tabular}{|c|c|c|c|}
\hline Material & Predicted Property & Modeling Technique & Reference \\
\hline SCBA & CS & GEP, multiple linear regression (MLR), MNLR & [14] \\
\hline FA & CS & ANN, ANFIS & [16] \\
\hline FA & CS & ANFIS, particle swarm optimization (SWO), genetic algorithm & [17] \\
\hline Ground granulated blast furnace slag (GGBFS) & CS & ANN & [19] \\
\hline FA and blast furnace slag (BFS) & CS & ANN & {$[20]$} \\
\hline FA & CS & GEP & {$[21]$} \\
\hline FA & CS & ANN, genetic programming (GP) & {$[22]$} \\
\hline SCBA & CS & Multiexpression programming (MEP) & [23] \\
\hline Corn cob ash (CCA) & CS & Taguchi and Taguchi-based gray relational analysis method (TGA) & {$[24]$} \\
\hline FA & Carbonation modeling & ANN & {$[25]$} \\
\hline Steel fiber-added lightweight concrete & CS & ANN & {$[26]$} \\
\hline Fiber-reinforced polymer concrete & Shear strength & ANN & {$[27]$} \\
\hline Fiber-reinforced polymer concrete & Shear strength & ANN & [28] \\
\hline High-strength concrete & CS & ANN & [29] \\
\hline
\end{tabular}




\section{Data Collection}

To accurately predict the CS of RHAC, a dataset of 192 data points from the literature was used to develop mathematical models [7,8,30-34]. The RHAC in the whole dataset consists of the same components which are as follows: OPC, RHA, aggregates, water, and superplasticizer (SP). The same types of cement and curing periods were used in all the mixes obtained from the literature.

A conversion factor of 0.8 (according to the standard BS 1881: Part 120:1983) was used to convert the CS of cubic specimens to the CS of cylinders. This research was focused on obtaining the CS of different mixes of RHAC through AI. Variables obtained from the literature such as the quantity of OPC (QOPC), percentage of SP, amount of water $(\mathrm{W})$, curing age (CA), amount of aggregates (AGG), and quantity of RHA (QRHA) were utilized as input parameters. Histograms for all the variables used in this study are shown in Figure 3. Furthermore, the statistical description of the obtained data is presented in Table 2.
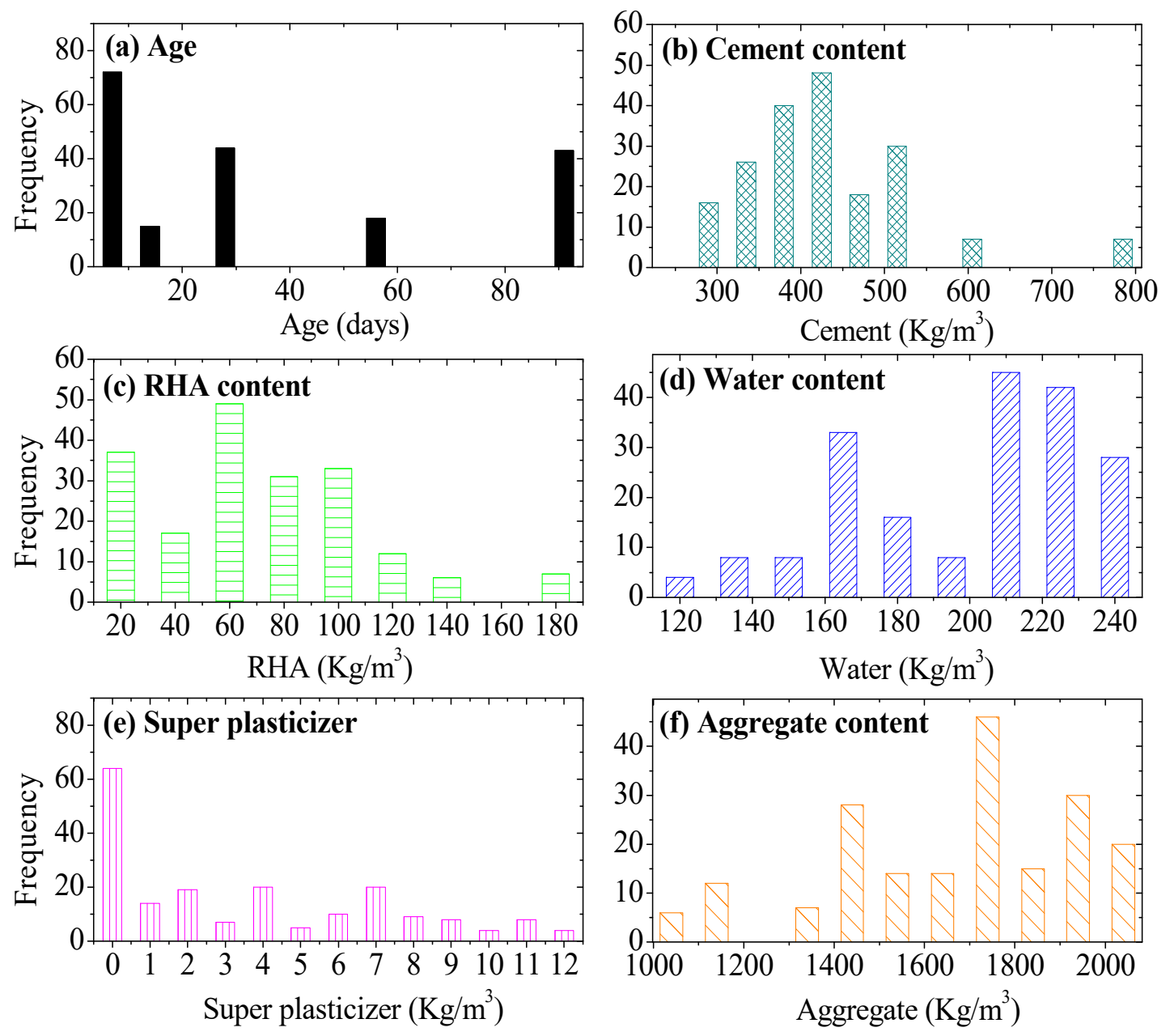

Figure 3. Frequency distribution histograms for: (a) age, (b) cement content, (c) RHA content, (d) water content, (e) superplasticizer, and (f) aggregate content. 
Table 2. Statistical analysis of input data.

\begin{tabular}{|c|c|c|c|c|c|c|c|}
\hline \multirow{2}{*}{$\begin{array}{l}\text { Statistical } \\
\text { Parameter }\end{array}$} & \multicolumn{6}{|c|}{ Input Parameters } & \multirow{2}{*}{$\begin{array}{c}\text { Output } \\
\text { Experimental } \\
\text { CS (MPa) }\end{array}$} \\
\hline & Age (Days) & $\begin{array}{l}\text { Cement } \\
\left(\mathrm{kg} / \mathrm{m}^{3}\right)\end{array}$ & $\underset{\left(\mathrm{kg} / \mathrm{m}^{3}\right)}{\text { RHA }}$ & $\begin{array}{c}\text { Water } \\
\left(\mathrm{kg} / \mathrm{m}^{3}\right)\end{array}$ & $\mathrm{SP}\left(\mathrm{kg} / \mathrm{m}^{3}\right)$ & $\begin{array}{c}\text { Aggregates } \\
\left(\mathrm{kg} / \mathrm{m}^{3}\right)\end{array}$ & \\
\hline Mean & 34.57 & 409.02 & 62.33 & 193.54 & 3.34 & 1621.51 & 48.14 \\
\hline Standard deviation & 33.52 & 105.47 & 41.55 & 31.93 & 3.52 & 267.77 & 17.54 \\
\hline Kurtosis & -1.02 & 3.66 & 0.07 & -0.74 & -0.82 & -0.27 & 0.75 \\
\hline Skewness & 0.75 & 1.55 & 0.44 & -0.42 & 0.69 & -0.74 & 0.83 \\
\hline Minimum & 1 & 249 & 0 & 120 & 0 & 1040 & 16 \\
\hline Maximum & 90 & 783 & 171 & 238 & 11.25 & 1970 & 104.1 \\
\hline
\end{tabular}

\section{Methodology}

The Methodology section provides brief details about the approaches taken to determine the CS of concrete mathematically. At first, the AI processes used in this research are explained. The results obtained from AI data processing techniques are assessed for validity by different statistical parameters.

\subsection{Modeling Techniques}

Different properties of materials can be assessed by using machine learning modeling techniques $[19,35,36]$. The mathematical models developed through these techniques suffice for the prediction of different properties without any elementary knowledge about the lab work or experiments. A brief introduction of modeling techniques used in this paper is provided in this section.

\subsubsection{Artificial Neural Network (ANN)}

As the name suggests, an artificial neural network's structure is based on the structure of the human brain network. It is a computer-based artificial technique for data analysis. There are different mechanisms in ANN which a researcher may use. However, one of the most common mechanisms is feedforward backpropagation (FFBP). An FFBP-type network essentially consists of three folds, namely, the input, black box, and output. These folds relate to each other through a proper sequence with the aid of different weights. The input fold only receives the data information of variables from outside, while the black box is a hidden fold where data get processed. These processed data are displayed to the viewer through the output fold $[37,38]$.

The FFBP can be further classified into single-layer perceptron (SLP) and multiplelayer perceptron (MLP). An SLP is simple and easy to use; however, it cannot be utilized to solve non-linear relations between inputs and outputs. On the other hand, an MLP is complex, yet it can solve the non-linear relations between different variables.

The process of an MLP has the following steps:

Step 1: The inputs are summed and weighted as

$$
s_{j}=\sum_{i=1}^{n} \omega_{i j} I_{i}+b j \quad j=1,2,3, \ldots \ldots, \mathrm{h}
$$

where $n=$ total number of inputs, $I_{i}=$ current input number, $\omega_{i j}=$ weight between the previous layer and jth neuron, and $b$ is used to define the tolerance.

Step 2: An activation function is utilized in this step to start the process. Various activation functions such as sigmoid, ramp, and Gaussian functions can be used in this step. However, this research utilized the sigmoid function, which can be written as

$$
s_{j}=\frac{1}{1+\mathrm{e}^{-s_{j}}} J=1,2,3, \ldots \ldots \ldots, \mathrm{h}
$$


Step 3: This step takes place during the outcome process. The final outputs depend on the calculations made in the black box. The outcome can be expressed as

$$
\begin{gathered}
O_{k}=\sum_{j=1}^{h}\left(\omega_{j k} \cdot s_{j}\right)+b_{k}^{\prime}, k=1,2, \ldots, m \\
O_{k}=\operatorname{sigmoid}\left(O_{k}\right)=\frac{1}{\left(1+\mathrm{e}^{-O_{k}}\right)}, \mathrm{k}=1,2, \ldots, \mathrm{m}
\end{gathered}
$$

In the above equation, $\omega_{j k}=$ weighted connection between $k$ th output node to $j$ th hidden node. Similarly, $b_{k}^{\prime}=$ bias output of kth output node.

In this research, $70 \%$ of the data points were selected randomly for training the data and $30 \%$ for validation.

\subsubsection{Artificial Neuro-Fuzzy Interface System (ANFIS)}

This technique utilizes an ANN as well as fuzzy logic [39]. The probability of error in outputs is minimized by an ANN, while the expert knowledge is expressed by fuzzy logic [19]. The conditional statements in programming are used to imply fuzzy logic rules. These conditional statements include if-then structures in programming. There are five layers in an ANFIS program (steps taking place in the ANFIS technique), namely: 1. fuzzification, 2. set of rules 3. normalization, 4 . defuzzification, 5. aggregation.

The fuzzification layer is the first layer. It contains the functional membership of all the input variables. The outcome in this layer is predicted by the Gaussian method. Mathematically, it can be written as

$$
\mu_{u i}(x)=\exp \left[-\frac{(x-a i)}{2 \varepsilon i^{2}}\right]
$$

where $a_{i}$ and $\varepsilon_{i}$ are parameters of a function membership.

Weighted nodes are present in the second layer. These weighted nodes multiply the inputs by some weights before forwarding them to layer 3. Fuzzy AND logic is used in this layer which can be expressed as

$$
w_{i}=\mu_{u i}(x) \times \mu_{v i}(y)
$$

Data are normalized and smoothened in the third layer. It normalizes the functional membership by calculating the ratios between different firing strengths using the following relation:

$$
\bar{w}=\frac{w_{i}}{\sum_{i} w_{i}}
$$

Defuzzification takes place in the fourth layer. Nodes present in this layer terminate the fuzzy logic rules. The square nodes of this layer can be expressed by the following function:

$$
\bar{w}_{i} f_{i}=w_{i} \times\left(m_{i} x+n_{i} y+r_{i}\right)
$$

where $m_{i}, n_{i}$, and $r_{i}$ are linear parameters.

Aggregation occurs in the fifth layer. It collects all the layers and presents the final outcome. Mathematically,

$$
\sum_{\mathrm{i}} \bar{w} f_{i}=\frac{\sum_{i} w_{i} f_{i}}{\sum_{i} w_{i}}
$$

MATLAB was used for ANFIS in this research. All the data points were used for training the data.

\subsubsection{Response Surface Methodology (RSM)}

RSM is a statistical technique that is used to model a relationship between the dependent (also known as a response) and independent (also known as factors) variables. RSM 
works in four steps: (a) designing an experiment, (b) performing the experiment, (c) developing a model based on inputs and outputs of experimental data, and (d) optimization of the model [40].

The following equation represents the RSM:

$$
Y=\beta_{0}+\sum_{i=1}^{k} \beta_{i} X_{i}+\sum_{i=1}^{k} \beta_{i i} X_{i}^{2}+\sum_{i, j} \beta_{i i} X_{i} X_{j}+\varepsilon
$$

where $\beta$ = coefficient, $K=$ number of observations, and $\varepsilon$ accounts for the error. The above equation can calculate an estimate for the value of $Y$ for each value of $X$.

\subsubsection{Linear Regression (LR)}

A linear relationship between the dependent and independent variables exists in this technique. It can be represented mathematically as

$$
Y=a+\beta_{1} X_{1}+\beta_{2} X_{2}+\beta_{3} X_{3}+\ldots \ldots+\beta_{i} X_{i}
$$

The above equation can be utilized to find values of $Y$ for each input value of $X$.

In Equations (10) and (11), $Y$ represents the output, that is, the CS of RHAC, and values of $X$ represent all the inputs such as age, QRHA, QOPC, AGG, W, and SP.

\section{Results}

A number of data points are constant for all the models and techniques. The set of 134 data points was used for training, and the set of 58 data points was used for validation.

\subsection{Artificial Neural Network (ANN)}

Parameters were adjusted before utilizing the ANN technique. These parameters were the training function for neural networks, iterations, number of hidden layers, the total number of neurons per hidden layer, and the maximum number of iterations. These parameters were determined through the hit and trial method in this research. A detail of the parametric adjustment is presented in Table 3.

Table 3. Parametric adjustments for ANN and ANFIS.

\begin{tabular}{ccc}
\hline \multirow{2}{*}{ Parameters } & \multicolumn{2}{c}{ Description } \\
\cline { 3 - 4 } & ANN & ANFIS \\
\hline Training function & Levenberg-Marquardt & trimf \\
\hline Total iterations & 3 & 6 \\
\cline { 1 - 1 } Training completed at iterations & 2 & 2 \\
\hline Total number of hidden layers & 2 & - \\
\hline
\end{tabular}

The CS of RHAC through the ANN was predicted by using MATLAB. The results predicted by the ANN are the closest to the experimental results. The similarity in the predicted and experimental results can be further verified by statistical parameters.

It can be observed that the correlation factor for the ANN-predicted CS $\left(R^{2}=0.98\right)$ is quite high. The prediction result for the ANN is shown in Figure 4. 


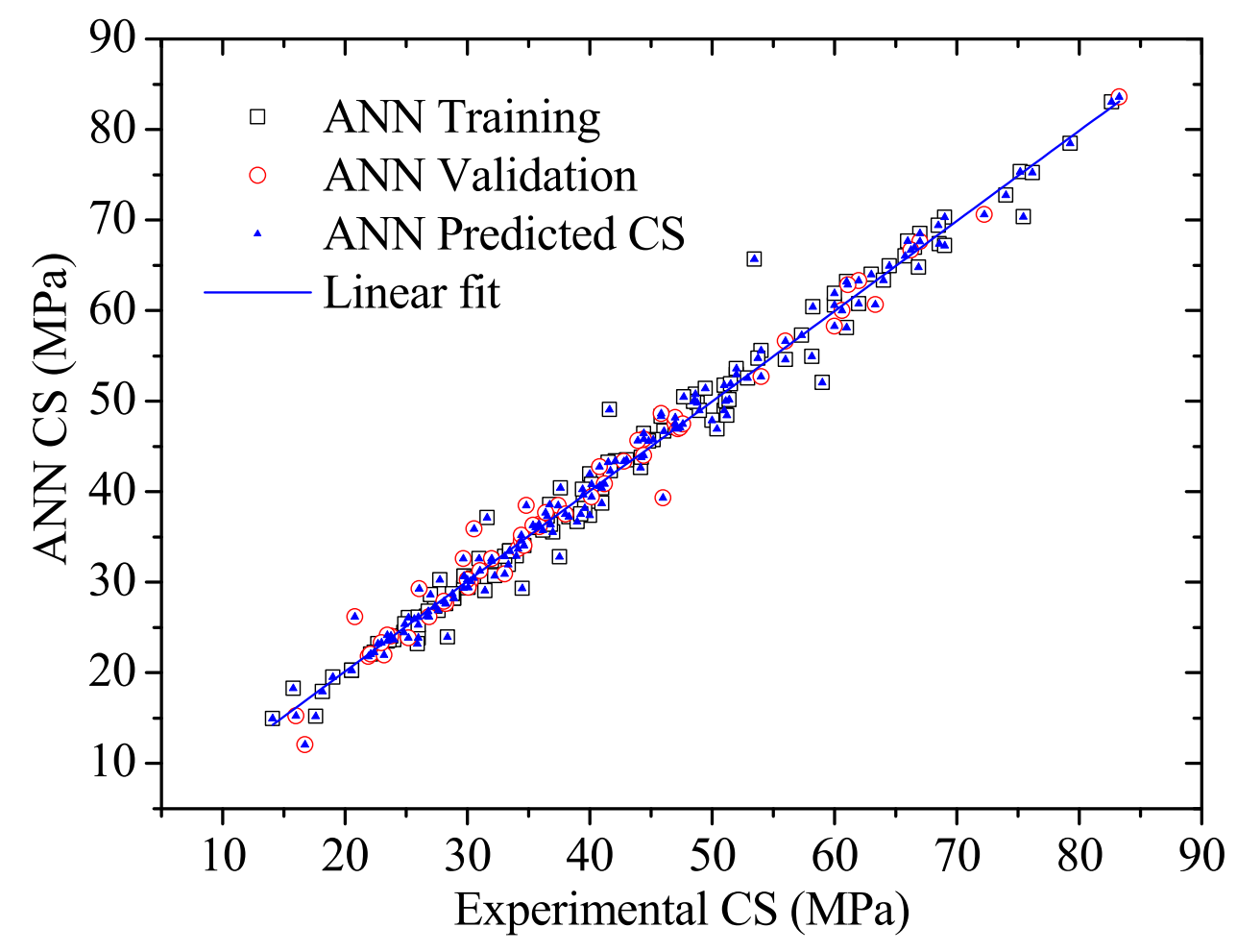

Figure 4. ANN: training, validation, and testing.

\subsection{Artificial Neuro-Fuzzy Interface System (ANFIS)}

The adjusted parameters, before using ANFIS, included the total number of iterations and the function used for activation of ANFIS. The parametric adjustments from the ANN and ANFIS are presented in Table 3.

MATLAB was used for ANFIS. The correlation factor for the ANFIS-predicted CS $\left(R^{2}=0.89\right)$ is high as well. Figure 5 illustrates the predicted results which are quite similar to the experimental ones.

\subsection{Response Surface Methodology (RSM)}

Figure 6 shows that the predicted CS by RSM is not close to the experimental values. The correlation factor for the RSM-predicted CS $\left(R^{2}=0.70\right)$ confirms the deviation in the results. The correlation factors for training and validation are also low (0.75 and 0.69, respectively), as observed by the dispersed points in Figure 6.

\subsection{Linear Regression (LR)}

The results predicted by LR are far from the experimental results. The weakest correlation of all techniques $\left(R^{2}=0.63\right)$ existed between the experimental and predicted results of LR. The correlation factors for LR training and LR validation were also low, at 0.64 and 0.62 , respectively. The dispersed points in Figure 7 confirm this. 


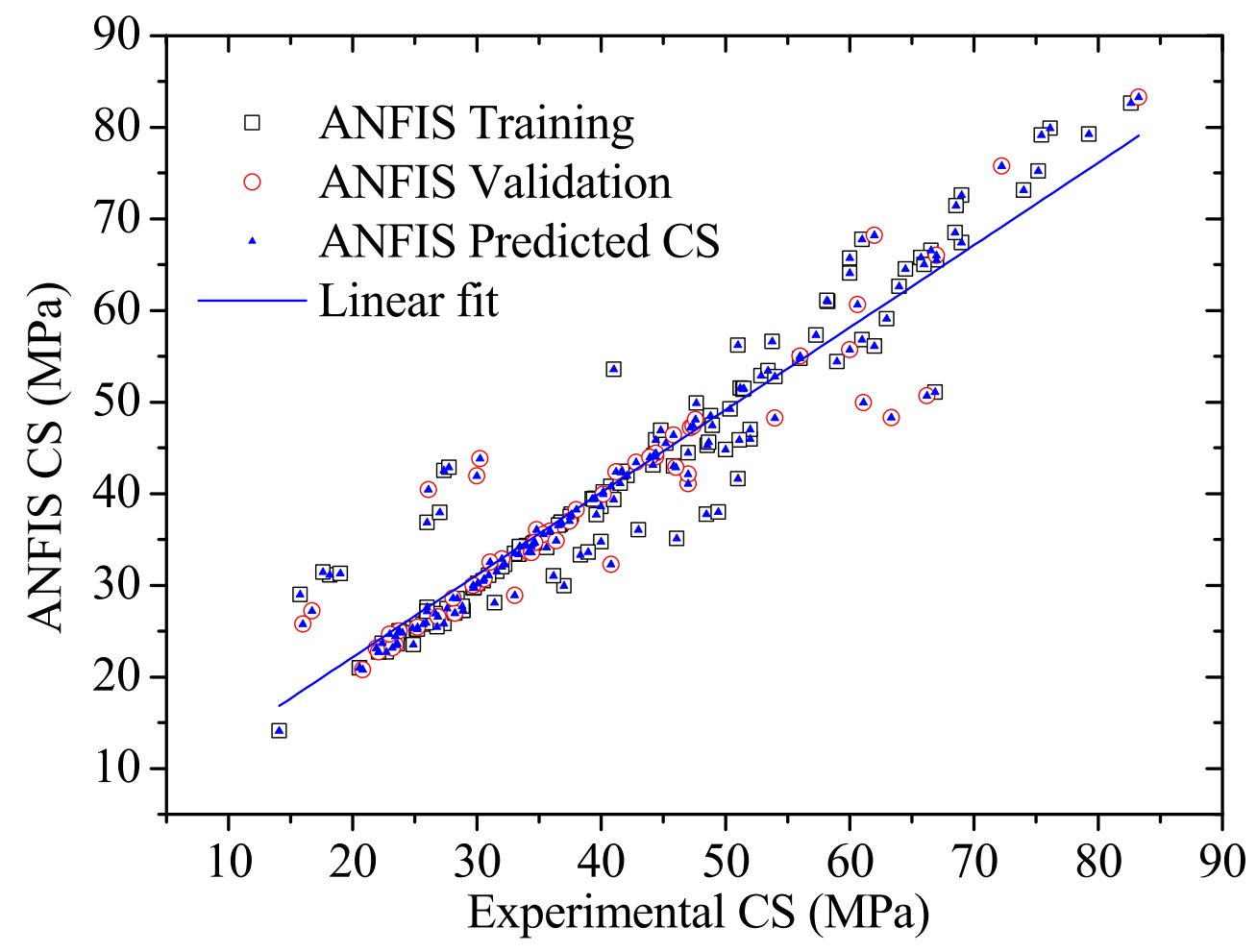

Figure 5. ANFIS: training, validation, and testing.

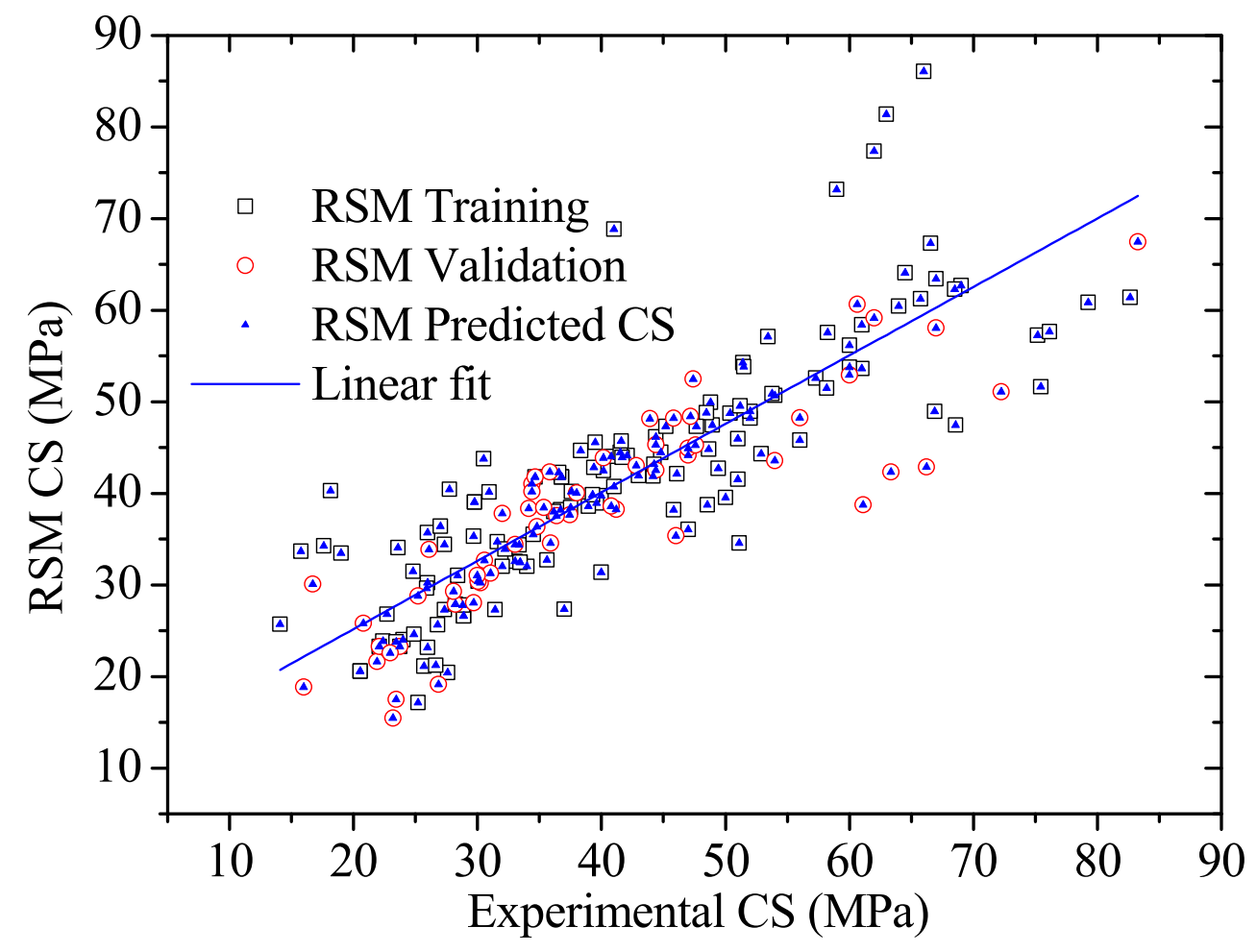

Figure 6. RSM: training, validation, and testing. 


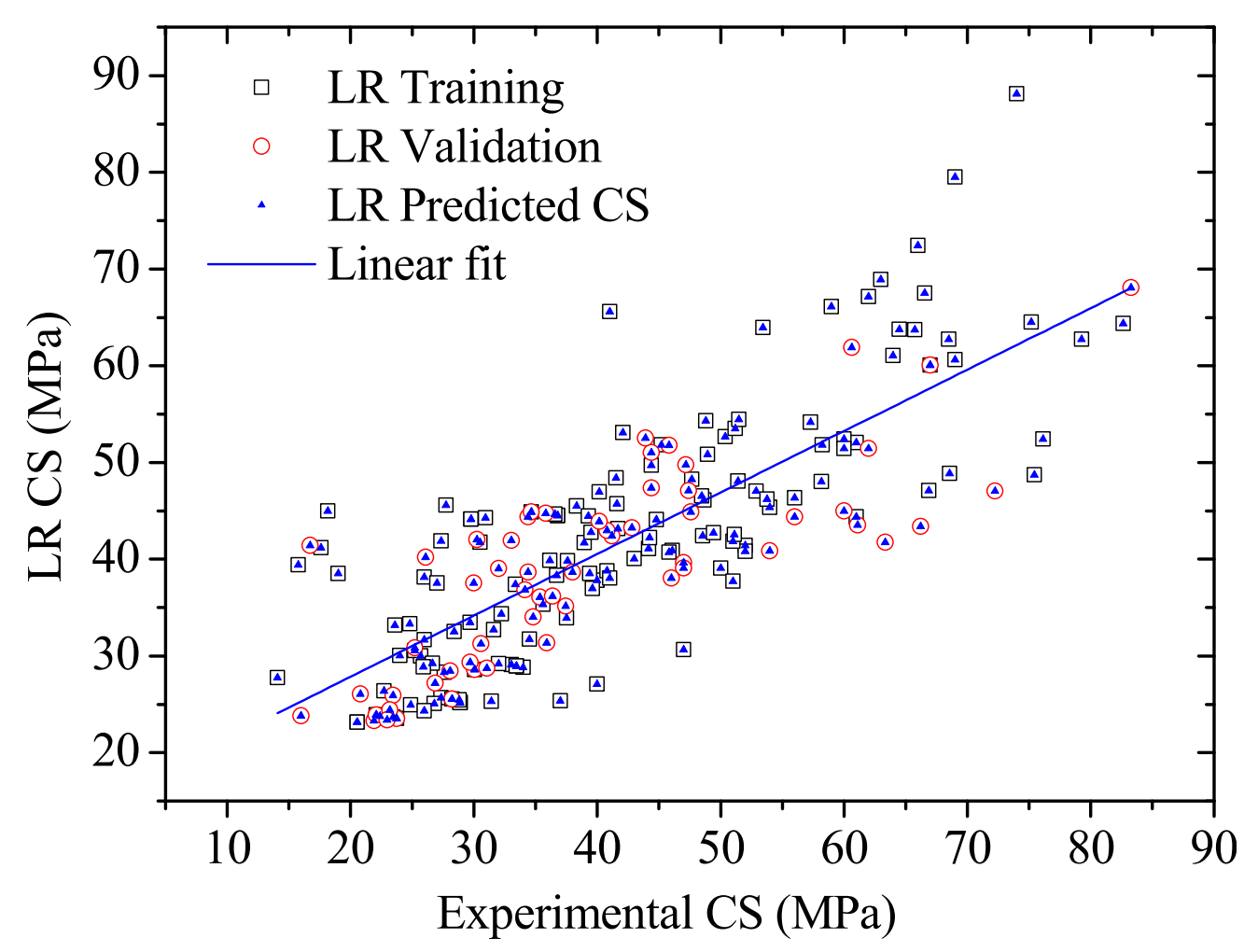

Figure 7. LR: training, validation, and testing.

\subsection{Sensitivity and Parametric Analysis}

The CS of RHAC was predicted by using different variables as input. The relative contribution of these variables to the outcome can be predicted by sensitivity analysis (SA). Mathematically, SA can be represented by using Equation (13), as shown below:

$$
\begin{gathered}
N_{i}=f_{\max }\left(x_{i}\right)-f_{\min }\left(x_{i}\right) \\
S A=\frac{N_{i}}{\sum_{n}^{j=1} N_{j}}
\end{gathered}
$$

where $f_{\max }\left(x_{i}\right)$. is the maximum and $f_{\min }\left(x_{i}\right)$ is the minimum output of the predictive models, whereas the input domain is represented by $i$, and other input variables are constant. It can be observed from Figure 8 that the different input variables affected the CS of RHAC in the same manner as that of the experimental method. 


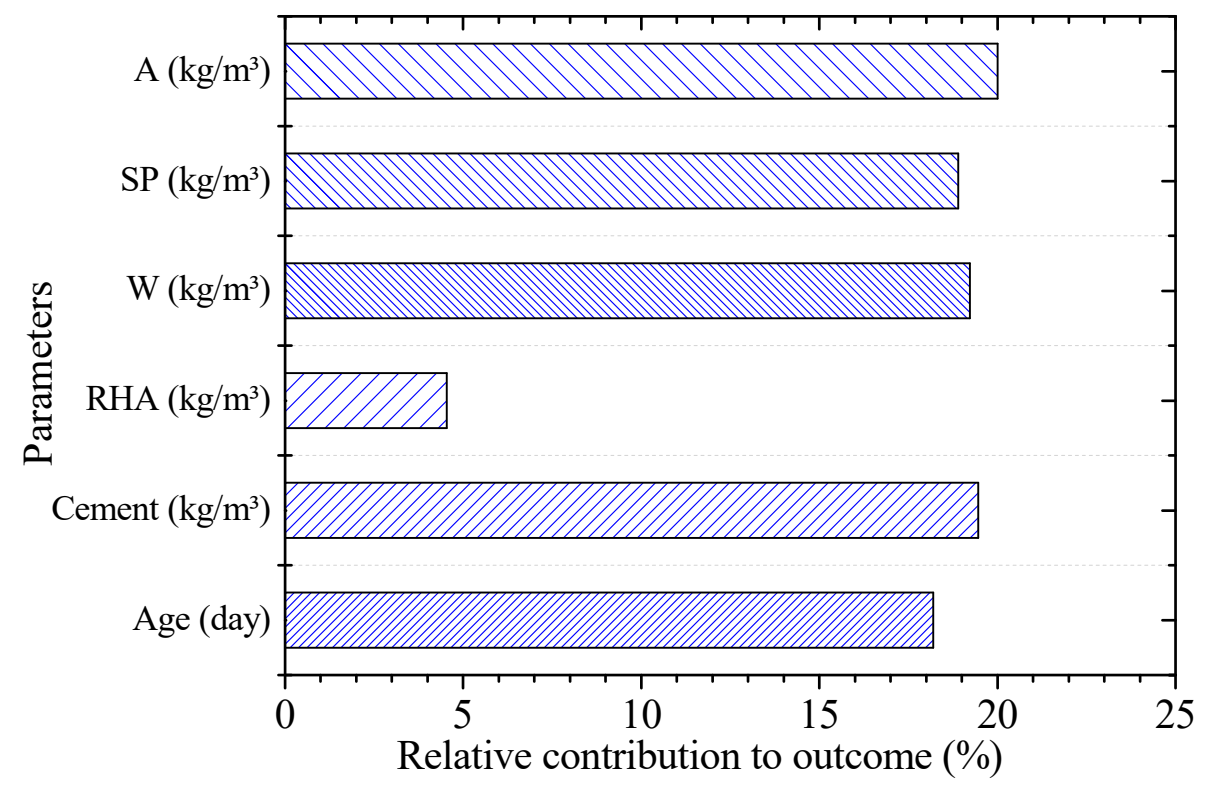

Figure 8. Contribution of inputs to the output.

Parametric analysis (PA) was also carried out along with SA. The main aim of PA is to determine the influence of input variables on the output parameter. In PA, all the input variables are kept constant at their mean value, except one input, and the trend of CS is noted for that variable input. All the results of PA are shown in Figure 9.
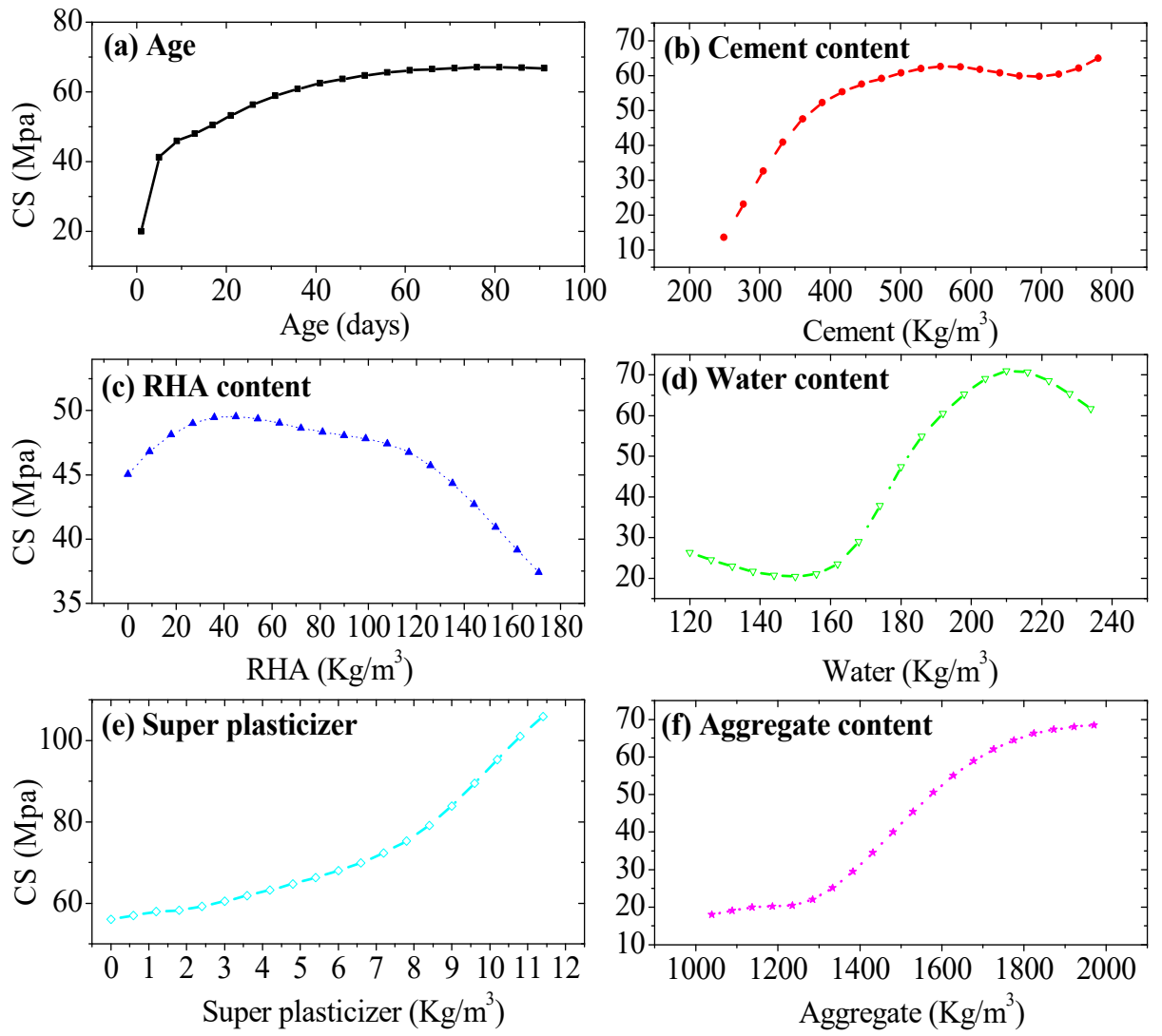

Figure 9. Parametric analysis of inputs: (a) age, (b) cement content, (c) RHA content, (d) water content, (e) superplasticizer, and (f) aggregate content. 
PA deemed that when water is increased from a certain amount, it adversely affects the CS of RHAC. This is obvious from the previous experimental studies as well. Sensale [34] conducted research in which two water-to-cement ratios $(\mathrm{w} / \mathrm{c})$ were analyzed. It was concluded that a w/c of 0.4 resulted in a higher CS than that of a w/c of 0.5.

It can also be observed from PA that QRHA contributes towards the enhancement of CS. However, when QRHA is increased from 15\%, it results in a decrease in the CS. This is because of the high silica content (90\%) of RHA and that the increase in QRHA results in an increment of silica. Therefore, this excessive silica remains unreacted and results in a reduced CS of RHAC [32].

From the discussion of the results, it can be concluded that the regression models do not accurately predict the CS as the predicted CS values were far from the experimental CS values, whereas the CS predicted by AI techniques was found to be in close agreement with the experimental results. This can be attributed to the fact that the pre-defined equations were used in a regression model that cannot learn the relationship between input variables and the function properly. However, contrary to the regression models, AI techniques learnt the relationship between inputs and the functions effectively and successfully. Hence, the machine learning techniques produced results closer to the experimental values.

\section{Conclusions}

Different models for the prediction of the CS of RHAC were developed in this study. The models developed in this study were based on a wide range of data which consist of different parameters demonstrated by experimental studies that are available in the literature. The models considered the most influential parameters on CS as inputs. The results obtained in this research are in close agreement with the experimental research. The following conclusions can be drawn from the obtained results:

1. It is evident by PA that the CS is efficiently predicted by the input parameters. In addition, the accuracy of data used at different stages such as training, validation, and testing is shown by $R^{2}$.

2. The results demonstrate $R^{2}$ values of $0.98,0.89,0.70$, and 0.63 for ANN, ANFIS, RSM, and LR, respectively. Therefore, it can be concluded, based on the results and statistical parameters, that the CS predicted by ANN and ANFIS is the most accurate among all AI techniques. Thus, these two AI techniques can be used for the predesign of RHAC.

3. The close agreement between the predicted and experimental results is in strong favor of employing AI techniques to use RHA in producing RHAC rather than disposing of it.

4. Using RHAC would contribute towards a green and sustainable environment by reducing the emission of carbon dioxide, cost, and emission of hazardous gases.

5. Utilization of RHA as a partial replacement of cement ultimately leads to lowering the carbon emissions from the cement industry. Therefore, it may be recommended that extensive research be carried out on RHAC to study the other important mechanical and durability-related properties such as the residual CS, behavior of steel with RHA, resistance to chloride, sulfate resistance, resistance to water penetration, and acid attacks. Many other AI techniques such as GEP, SVM, and ELM can also be used to propose further predictions.

Author Contributions: M.N.A., K.K., F.I.S. and M.G.Q. contributed to the design of this research project. A.I., M.F.J., M.N.A. and K.K. contributed to ANN modeling, critically analyzed and discussed the results of this research, and contributed to preparing the initial draft of the manuscript. F.I.S. and M.G.Q. reviewed the initial draft. A.I., M.F.J., M.N.A. and K.K. edited and prepared the final draft of this manuscript. At the revision stage, M.N.A., M.G.Q. and A.I. contributed to the revision, and M.N.A. prepared the final revised manuscript. All authors have read and agreed to the published version of the manuscript. 
Funding: This research was funded by the Deanship of Scientific Research at King Faisal University through its group research grant number (1811011).

Institutional Review Board Statement: Not applicable.

Informed Consent Statement: Not applicable.

Data Availability Statement: The data presented in this study are available on request from the corresponding author.

Acknowledgments: The authors acknowledge the Deanship of Scientific Research at King Faisal University, Al-Ahsa, Saudi Arabia, for the financial support under the Research Group Support Track (Grant No. 1811011).

Conflicts of Interest: The authors declare no conflict of interest. The funders had no role in the design of the study; in the collection, analyses, or interpretation of data; in the writing of the manuscript, or in the decision to publish the results.

\section{References}

1. Chen, C.; Habert, G.; Bouzidi, Y.; Jullien, A. Environmental impact of cement production: Detail of the different processes and cement plant variability evaluation. J. Clean. Prod. 2010, 18, 478-485. [CrossRef]

2. Mahlia, T. Emissions from electricity generation in Malaysia. Renew. Energy 2002, 27, 293-300. [CrossRef]

3. Zhang, X.F.; Zhang, S.Y.; Hu, Z.Y.; Yu, G.; Pei, C.H.; Na Sa, R. Identification of connection units with high GHG emissions for low-carbon product structure design. J. Clean. Prod. 2012, 27, 118-125. [CrossRef]

4. Gagg, C.R. Cement and concrete as an engineering material: An historic appraisal and case study analysis. Eng. Fail. Anal. 2014, 40, 114-140. [CrossRef]

5. Khan, K.; Ullah, M.F.; Shahzada, K.; Amin, M.N.; Bibi, T.; Wahab, N.; Aljaafari, A. Effective use of micro-silica extracted from rice husk ash for the production of high-performance and sustainable cement mortar. Constr. Build. Mater. 2020, $258,119589$. [CrossRef]

6. Parveen, S.; Pham, T.M. Enhanced properties of high-silica rice husk ash-based geopolymer paste by incorporating basalt fibers. Constr. Build. Mater. 2020, 245, 118422. [CrossRef]

7. Ameri, F.; Shoaei, P.; Bahrami, N.; Vaezi, M.; Ozbakkaloglu, T. Optimum rice husk ash content and bacterial concentration in self-compacting concrete. Constr. Build. Mater. 2019, 222, 796-813. [CrossRef]

8. Chao-Lung, H.; Le Anh-Tuan, B.; Chun-Tsun, C. Effect of rice husk ash on the strength and durability characteristics of concrete. Constr. Build. Mater. 2011, 25, 3768-3772. [CrossRef]

9. Chindaprasirt, P.; Kanchanda, P.; Sathonsaowaphak, A.; Cao, H. Sulfate resistance of blended cements containing fly ash and rice husk ash. Constr. Build. Mater. 2007, 21, 1356-1361. [CrossRef]

10. Thomas, B.S. Green concrete partially comprised of rice husk ash as a supplementary cementitious material—A comprehensive review. Renew. Sustain. Energy Rev. 2018, 82, 3913-3923. [CrossRef]

11. Gursel, A.P.; Maryman, H.; Ostertag, C. A life-cycle approach to environmental, mechanical, and durability properties of "green" concrete mixes with rice husk ash. J. Clean. Prod. 2016, 112, 823-836. [CrossRef]

12. Moraes, C.A.M.; Kieling, A.G.; Caetano, M.O.; Gomes, L.P. Life cycle analysis (LCA) for the incorporation of rice husk ash in mortar coating. Resour. Conserv. Recycl. 2010, 54, 1170-1176. [CrossRef]

13. Saraswathy, V.; Song, H.-W. Corrosion performance of rice husk ash blended concrete. Constr. Build. Mater. 2007, 21, 1779-1784. [CrossRef]

14. Javed, M.F.; Amin, M.N.; Shah, M.I.; Khan, K.; Iftikhar, B.; Farooq, F.; Aslam, F.; Alyousef, R.; Alabduljabbar, H. Applications of Gene Expression Programming and Regression Techniques for Estimating Compressive Strength of Bagasse Ash based Concrete. Crystals 2020, 10, 737. [CrossRef]

15. Shahmansouri, A.A.; Yazdani, M.; Ghanbari, S.; Bengar, H.A.; Jafari, A.; Ghatte, H.F. Artificial neural network model to predict the compressive strength of eco-friendly geopolymer concrete incorporating silica fume and natural zeolite. J. Clean. Prod. 2021, 279, 123697. [CrossRef]

16. Van Dao, D.; Ly, H.-B.; Trinh, S.H.; Le, T.-T.; Pham, B.T. Artificial Intelligence Approaches for Prediction of Compressive Strength of Geopolymer Concrete. Materials 2019, 12, 983. [CrossRef]

17. Van Dao, D.; Trinh, S.H.; Ly, H.-B.; Pham, B.T. Prediction of Compressive Strength of Geopolymer Concrete Using Entirely Steel Slag Aggregates: Novel Hybrid Artificial Intelligence Approaches. Appl. Sci. 2019, 9, 1113. [CrossRef]

18. Zhang, J.; Li, D.; Wang, Y. Predicting uniaxial compressive strength of oil palm shell concrete using a hybrid artificial intelligence model. J. Build. Eng. 2020, 30, 101282. [CrossRef]

19. Ganesh, A.C.; Muthukannan, M. Development of high performance sustainable optimized fiber reinforced geopolymer concrete and prediction of compressive strength. J. Clean. Prod. 2021, 282, 124543. [CrossRef]

20. Atici, U. Prediction of the strength of mineral admixture concrete using multivariable regression analysis and an artificial neural network. Expert Syst. Appl. 2011, 38, 9609-9618. [CrossRef] 
21. Khan, M.A.; Zafar, A.; Akbar, A.; Javed, M.; Mosavi, A. Application of Gene Expression Programming (GEP) for the Prediction of Compressive Strength of Geopolymer Concrete. Materials 2021, 14, 1106. [CrossRef]

22. Nguyen, K.; Nguyen, Q.D.; Le, T.A.; Shin, J.; Lee, K. Analyzing the compressive strength of green fly ash based geopolymer concrete using experiment and machine learning approaches. Constr. Build. Mater. 2020, 247, 118581. [CrossRef]

23. Shah, M.I.; Memon, S.A.; Niazi, M.S.K.; Amin, M.N.; Aslam, F.; Javed, M.F. Machine Learning-Based Modeling with Optimization Algorithm for Predicting Mechanical Properties of Sustainable Concrete. Adv. Civ. Eng. 2021, 2021, 1-15. [CrossRef]

24. Arıc1, E.; Çelik, E.; Keleştemur, O. A performance evaluation of polypropylene fiber-reinforced mortars containing corn cob ash exposed to high temperature using the Taguchi and Taguchi-based Grey Relational Analysis methods. Constr. Build. Mater. 2021, 297, 123792. [CrossRef]

25. Felix, E.F.; Carrazedo, R.; Possan, E. Carbonation model for fly ash concrete based on artificial neural network: Development and parametric analysis. Constr. Build. Mater. 2021, 266, 121050. [CrossRef]

26. Altun, F.; Özgür, K.; Aydin, K. Predicting the compressive strength of steel fiber added lightweight concrete using neural network. Comput. Mater. Sci. 2008, 42, 259-265. [CrossRef]

27. Perera, R.; Barchín, M.; Arteaga, A.; De Diego, A. Prediction of the ultimate strength of reinforced concrete beams FRPstrengthened in shear using neural networks. Compos. Part B Eng. 2010, 41, 287-298. [CrossRef]

28. Tanarslan, H.; Secer, M.; Kumanlioglu, A. An approach for estimating the capacity of RC beams strengthened in shear with FRP reinforcements using artificial neural networks. Constr. Build. Mater. 2012, 30, 556-568. [CrossRef]

29. Öztaş, A.; Pala, M.; Özbay, E.; Kanca, E.; Çaglar, N.; Bhatti, M.A. Predicting the compressive strength and slump of high strength concrete using neural network. Constr. Build. Mater. 2006, 20, 769-775. [CrossRef]

30. Bui, D.; Hu, J.; Stroeven, P. Particle size effect on the strength of rice husk ash blended gap-graded Portland cement concrete. Cem. Concr. Compos. 2005, 27, 357-366. [CrossRef]

31. Ganesan, K.; Rajagopal, K.; Thangavel, K. Rice husk ash blended cement: Assessment of optimal level of replacement for strength and permeability properties of concrete. Constr. Build. Mater. 2008, 22, 1675-1683. [CrossRef]

32. Ramezanianpour, A.A.; Mahdikhani, M.; Ahmadibeni, G.H. The effect of rice husk ash on mechanical properties and durability of sustainable concretes. Int. J. Civ. Eng. 2009, 7, 83-91.

33. Sakr, K. Effects of Silica Fume and Rice Husk Ash on the Properties of Heavy Weight Concrete. J. Mater. Civ. Eng. 2006, 18, 367-376. [CrossRef]

34. de Sensale, G.R. Strength development of concrete with rice-husk ash. Cem. Concr. Compos. 2006, 28, 158-160. [CrossRef]

35. Golafshani, E.M.; Behnood, A.; Arashpour, M. Predicting the compressive strength of normal and High-Performance Concretes using ANN and ANFIS hybridized with Grey Wolf Optimizer. Constr. Build. Mater. 2020, 232, 117266. [CrossRef]

36. Golafshani, E.M.; Behnood, A. Automatic regression methods for formulation of elastic modulus of recycled aggregate concrete. Appl. Soft Comput. 2018, 64, 377-400. [CrossRef]

37. Gandomi, A.; Roke, D.A. Assessment of artificial neural network and genetic programming as predictive tools. Adv. Eng. Softw. 2015, 88, 63-72. [CrossRef]

38. Alavi, A.H.; Gandomi, A.H. Prediction of principal ground-motion parameters using a hybrid method coupling artificial neural networks and simulated annealing. Comput. Struct. 2011, 89, 2176-2194. [CrossRef]

39. Çaydaş, U.; Hasçalık, A.; Ekici, S. An adaptive neuro-fuzzy inference system (ANFIS) model for wire-EDM. Expert Syst. Appl. 2009, 36, 6135-6139. [CrossRef]

40. Zhang, Q.; Feng, X.; Chen, X.; Lu, K. Mix design for recycled aggregate pervious concrete based on response surface methodology. Constr. Build. Mater. 2020, 259, 119776. [CrossRef] 